\section{$\underset{\substack{\text { hommes } \\ \text { \& migrations }}}{ }$}

\section{Hommes \& migrations}

Revue française de référence sur les dynamiques

migratoires

Musulmanes et féministes en Grande-Bretagne

\title{
Daryush Shayegan, La Conscience métisse
}

Paris, Albin Michel, 2012, 258 pages, 22 euros

\section{Mustapha Harzoune}

\section{(2) OpenEdition}

1 Journals

\section{Édition électronique}

URL : http://journals.openedition.org/hommesmigrations/1442

DOI : 10.4000/hommesmigrations. 1442

ISSN : 2262-3353

Éditeur

Musée national de l'histoire de l'immigration

Édition imprimée

Date de publication : 1 septembre 2012

Pagination : 154-155

ISSN : 1142-852X

Référence électronique

Mustapha Harzoune, «Daryush Shayegan, La Conscience métisse », Hommes \& migrations [En ligne],

1299 | 2012, mis en ligne le 29 mai 2013, consulté le 22 septembre 2020. URL : http://

journals.openedition.org/hommesmigrations/1442; DOI : https://doi.org/10.4000/

hommesmigrations. 1442

Ce document a été généré automatiquement le 22 septembre 2020.

Tous droits réservés 


\title{
Daryush Shayegan, La Conscience métisse
}

Paris, Albin Michel, 2012, 258 pages, 22 euros

\author{
Mustapha Harzoune
}

\section{RÉFÉRENCE}

Daryush Shayegan, La Conscience métisse, Paris, Albin Michel, 2012, 258 pages, 22 euros.

1 On connaît Daryush Shayegan et son infatigable travail de passeur, entre les espaces et entre les temps, cet éveilleur à cette conscience métisse que la féministe indienne Chendra Talpade Mohantry définie comme "une conscience des lisières, voire une conscience plurielle dans la mesure où elle exige une compréhension multiple des idées souvent opposées et un besoin de négocier ces connaissances sans prendre de position contre". La conscience métisse appelle les notions d"'identité plurielle", de "zone d'hybridation", de “ virtualisation", de "monde kaléidoscopique", "fragmenté, discontinu, fractal, rhizomatique", d"interconnectivité (la loi de la causalité dépendante)" en phase avec la "réalité multicuturelle, multidépendante de notre civilisation mondiale où tout éclate en quantas d'existences, en quantas d'identités croisées, en moments interactifs de communication". Cet ouvrage rassemble dix textes et trois entretiens. Impressionnante machine intellectuelle au savoir encyclopédique, Shayegan traite aussi bien de la philosophie occidentale avec Foucault (la notion d'écart), Deleuze (et le rhizome), Baudrillard (pour les nouvelles technologies ou le terrorisme), que des traditions spirituelles d'Orient avec Rûzbahân Baqlî Shîrazî (XII siècle) ou Hafez de Shiraz (XIVe siècle); passe de la réception d'Heidegger en Iran à la figure encyclopédique de Mollâ Sadrâ; du XVe siècle européen et la naissance de la science moderne aux "bricolages" modernes, cet "art combinatoire par excellence", dont il trouve des exemples "dans les romans anglo-indiens, latino-américains, [ou] parmi les adhérents du New Age". Au cœur de cet ouvrage souvent difficile mais utile et stimulant, l'auteur décortique le lien entre l'Orient (entendre ici le vaste monde arabe et iranien) et l'Occident, réaffirmant l'universalité de certaines 
valeurs qui, pour être nées en Europe, n'en seraient pas moins aujourd'hui patrimoine de l'humanité. Les identités plurielles ne sont pas l'apanage de quelques happy few du Nord développé ou de ces générations d'étourneaux échappées des semelles de vent de leurs parents nomades. Pour l'auteur, les sociétés du Sud sont aussi traversées par ces identités plurielles et à ce titre elles portent une identité occidentale. De ce point de vue, "le vent de liberté qui a soufflé récemment sur le monde arabe présage là aussi un espoir, espoir que, quelque particularité culturelle et religieuse que nous ayons les uns et les autres, il existe toutefois des valeurs qui transcendent ces particularismes nationaux et ethniques et concernent l'humanité tout entière". Et de citer parmi ces valeurs universelles: la raison; la séparation des pouvoirs; l'habeas corpus ; la pensée critique contre les intolérances dogmatiques, mais aussi "un certain libéralisme tolérant tempéré par la sécurité et la justice des lois sociales comme 'meilleur ordre rentable' pour gérer l'économie". Pour Shayegan, "ces valeurs universelles, neutres idéologiquement, libres de toutes couleurs confessionnelles, constituent en soi une nouvelle identité", "le patrimoine de toute l'humanité". Pour autant, cette universalité qui travaillerait chaque société aujourd'hui métissée, chaque identité fragmentée, ne va pas sans débats, parfois même sans désordres intérieurs, une sorte de "schizophrénie" où chacun doit apprendre à faire le tri, progresser entre les concepts, les références, organiser un dialogue permanent entre les cultures - celles du cru et d'ailleurs. D'autant plus difficile qu'à cela s'ajoute la logique des sédimentations, ces sédiments que la modernité a pu faire taire, un temps, mais qui restent là, présents, ne demandant qu'à remonter à la surface à la moindre occasion, pour le pire (l'Europe en fit l'expérience au XXe siècle) ou pour le meilleur ("le souvenir des identités oubliées sous les sables de la mondialisation", le réveil de certaines valeurs opposées aux seules règles du profit)."Un homme qui cumule ces mondes hétérogènes doit disposer d'un clavier de décodage, d'une boîte à outils pour qu'on arrive à apprivoiser sa schizophrénie et ses contradictions, à montrer enfin distinctement la palette somptueuse de ces différentes sensibilités, riches en sève immémoriale, et, ce qui est encore plus crucial, à vivre simultanément et sereinement des mondes antithétiques, historiquement non contemporains. Cela est un avantage indéniable pour celui qui sait en profiter et qui s'est débarrassé de ses complexes et tabous ataviques. Mais pour pouvoir recourir à cette méthode, qui relève un peu de l'acrobatie mentale, il faut savoir sortir de son orbite culturelle, prendre du recul à l'égard de ses propres coordonnées métaphysiques, scruter ces croisements ludiques des regards par le truchement de son identité moderne." C'est dire si les travaux de Shayegan exigent une pédagogie, à l'adresse des peuples et des individus, notamment pour celles et ceux qui, nés au croisement de multiples trajectoires, s'égarent dans la géométrie labyrinthique des identités modernes et se réfugient dans quelques fictions linéaires et émollientes. $\mathrm{Ce}$ que disent ces textes, encore une fois d'une haute volée intellectuelle, lus au ras du bitume des cités mais aussi au pied des estrades de politiciens pyromanes, c'est l'urgence : le monde à changé, les êtres sont devenus plus composites, il faut les aider à comprendre leur environnement, leur histoire, leur rapport aux autres, toucher du doigt ces fragmentations qui les habitent et les constituent. La conscience métisse, en ce qu'elle traduit d'abord la condition métisse, est une conscience exigeante. Difficile. Instable. Peu sécurisante. Rien à voir avec le prêt à penser idéologique ou religieux qui a réponse à tout ... Il faut enseigner la pensée métisse pour aider à vivre. Pour aider à mieux vivre ensemble. Il faut l'enseigner sur les bancs des écoles. Aux pédagogues (et aux responsables) de s'activer pour fournir à tout un chacun les outils permettant de comprendre ces notions de "mémoire récapitulative"; comprendre pourquoi la diversité culturelle (et religieuse) exige des règles démocratiques et des société laïques ; 
apprendre à ne pas confondre culture et identité ethnique; substituer aux relations "monologiques" entre les êtres et les cultures des relations "dialogiques"; savoir être attentif aux zones de rencontre, d'hybridation, où s'élaborent des métissages nouveaux, de nouvelles identités; comprendre pourquoi il est urgent d'en finir avec les logiques $\mathrm{du}$ ressentiment et des boucs émissaires - Shayegan note chez les manifestants du monde arabe et iranien l'"absence de ressentiment contre ceci ou contre cela comme si on voulait briser le cercle vicieux échec-humiliation-ressentiment". C'est cet art de la bricole, du "bricolage", "l'art combinatoire des relations multiples à tous les niveaux et le jeu des miroirs croisés” qu'il faut enseigner. L'enjeu n'est pas de rafistoler la petite clôture de son pré carré, mais de contribuer à consolider un monde en gestation. 